\title{
CONCEPTION OF DESIGN PRINCIPLES FOR ADDITIVE MANUFACTURING
}

\author{
Valjak, Filip; Bojčetić, Nenad \\ University of Zagreb
}

\begin{abstract}
Additive Manufacturing (AM) brought new design freedom and possibilities that enable design and manufacturing of products with new forms and functionalities. To utilise these possibilities a new design approach emerged, Design for Additive Manufacturing (DfAM), that contains methods and tools for supporting AM oriented design process. Designers working with AM are aware of the need to apply DfAM and AM possibilities in conceptual design phase where they have the most significant influence on product architecture and form but are facing a lack of suitable DfAM approaches for early design phases. Therefore, the presented research is investigating possibilities of storing and representing AM knowledge in the form of design principles to be used in the conceptual design phase. The paper proposes conceiving of Design Principles for Additive Manufacturing repository where formalised AM knowledge is stored in the form of design principles and structured based on function criteria. In the paper, various elements of design principle representation are discussed, as well as their role in the conceptual design process.
\end{abstract}

Keywords: Design for Additive Manufacturing (DfAM), Design principles, Functional modelling, Additive Manufacturing

\section{Contact:}

Valjak, Filip

University of Zagreb, FSB

Department of Design

Croatia

fvaljak@fsb.hr

Cite this article: Valjak, F., Bojčetić, N. (2019) 'Conception of Design Principles for Additive Manufacturing', in Proceedings of the 22nd International Conference on Engineering Design (ICED19), Delft, The Netherlands, 5-8 August 2019. DOI:10.1017/dsi.2019.73 


\section{INTRODUCTION}

Additive manufacturing (AM) is a manufacturing technology that started as a rapid prototyping technology but nowadays it is an everyday technology used by an increasing number of companies, not only for prototyping but also for production of final products distributed to the consumers (Thompson et al., 2016). Through its characteristic of adding material precisely where it is needed, AM brought new design possibilities and freedom that manifests in new functionalities and shapes of AM products (Gibson et al., 2015). The changes in the way of how the new products are manufactured, but also potential changes in the design of those products are challenges that designers are facing while designing AM products (Seepersad, 2014). To understand the implications AM imposed on the design process and to help designers in the utilisation of AM potentials a new design approach emerged - Design for Additive Manufacturing (DfAM). DfAM is design criteria focused on specificities of AM, as well as its limitations, that through a set of methods and tools guide designers and support design process of products with new functions, forms and material compositions that are enabled with AM (Laverne et al., 2015; Yang et al., 2016). Today, DfAM offer a broad spectrum of approaches that utilise AM possibilities in various design phases. As AM enables the creation of products with new forms and functionalities, to take advantage of AM possibilities, it is important to utilise them early in the design process. Designers working with AM recognise this importance, and acknowledge the need to apply DfAM and AM possibilities in conceptual design, although in practice DfAM is mostly used in the embodiment and detail design (Pradel et al., 2018a). The importance of conceptual design in any design approach, including DfAM, emerges from activities of establishing a functional and working structure that have vast influence on the embodiment and detail design of a product (Pahl et al., 2007). This is a reason why most design studies about the conceptual design phase have been focused on functions that model expected product behaviour (Ko and Moon, 2017). For the same reasons, functional modelling is an integral part of the conceptual phase inside the DfAM framework proposed by Kumke et al. (2016). Although the conceptual phase and functional modelling play an important role in the design process, literature sources show the lack of DfAM approaches for the conceptual design (Pradel et al., 2018b). Therefore, there is a need for the development of methods and tools to aid designers in the conceptual design for AM. Furthermore, designers, especially novices in AM design, need sources of design knowledge about AM and its possibilities in an AM oriented design process.

For these reasons, presented research is focused on the conceptual phase of an AM design and its functions, as "form follows function" (Ullman, 2010). To support the conceptualisation and a systematic approach to DfAM, conception of Design Principles for Additive Manufacturing (DPAM) repository as a form of storing AM related design knowledge categorised around product functions is proposed. The paper examines the current DfAM methods and ways of storing AM design knowledge in Section 2. In Section 3 method and sources for deriving design principles are presented. The elements of design principle representation are explained in Section 4, followed by examples of derived design principles in Section 5. Section 6 discusses DPAM, elements of design principles representation and their influence on conceptual design and designers, while conclusion and guidelines for future work are given in Section 7.

\section{BACKGROUND \& RELATED WORK}

In the design domain, design knowledge can be formalised in few knowledge explications, such as guidelines, heuristics, principles, rules of thumb and strategic constructs (Fu et al., 2015, 2016), each with specificity regarding a level of representation and source of knowledge. The same explications are used in DfAM to formalise AM specific design knowledge for early design phases (Pradel et al., $2018 \mathrm{~b}$ ). One of the first attempts to formalise AM knowledge and provide design guidance in the conceptual design was the AM design feature database proposed by Bin Maidin et al. (2012). In this approach, features are captured and classified in four taxons based on the reasons for using AM and described by title, application, functionality keywords and 3D model. Besides enabling inexperienced designers to understand the specificities of AM, the design features database proved itself as a useful tool for the conceptualisation of AM products. On the other hand, an example of design heuristics is a list of twenty-nine process independent AM heuristics developed by Blösch-Paidosh and Shea (2017). The heuristics formalise AM knowledge on a high level of abstraction and are aiming to stimulate 
designers' creativity to create concepts that incorporate functionalities enabled with AM. Lindwall and Törlind (2018) reduced the list on ten heuristics and afterwards conducted the user study to investigate their influence on the design process. The study showed the usefulness of heuristics as a tool in the designing process, they stimulate designers to think about the possibilities of AM and how to incorporate them into their designs. The influence of the full list of AM heuristics on the designers' creativity was further observed through the study conducted by Blösch-Paidosh and Shea (2018). The study showed the positive influence of AM heuristics on the generated designs in the early phases of the design process. Another approach in DfAM to formalise AM knowledge are design principles presented in the form of the design catalogue of AM solutions proposed by Weiss et al. (2016). In the catalogue AM knowledge is formalised in the form of principle solutions that are classified according to functions they are solving. When using the catalogue designers are looking for partial solutions for a given problem, by searching for sub-function of a decomposed overall function of the design problem. Besides principle solutions, design catalogue provides additional information such as textual and visual (2D) descriptions, manufacturability data for various AM process, as well as the comparisons to conventional designs.

Although current developments in DfAM offer various approaches in formalising AM design knowledge for early design stages, they are not without limitations. The design feature database, for example, does not consider all possibilities of AM, it mostly focuses on outer form and user fit requirements. On the other hand, heuristics offer a broad spectrum of AM knowledge on a higher level of abstraction. However, as heuristics are based on intuition and tacit knowledge, they provide design guidance but do not guarantee a solution (Fu, 2016). Design principles, on the other hand, are based on empirical evidence and can help designers find a successful solution ( $\mathrm{Fu}, 2016)$. This can be seen in the proposed design catalogue (Weiss et al., 2016), where solutions are found through function criteria. Although this simplifies the search for the solutions, as the used functions definitions are not based on formal vocabulary, there is a possibility of various definitions for the same function that could cause the misunderstanding in classifying solutions. Furthermore, as the design principles are stored in the design catalogue, their representation is limited to $2 \mathrm{D}$ visualisation and textual descriptions.

Because the design principles provide an adequate form for storing design knowledge needed in conceptual design, this study examines the elements of its representation and storing of AM knowledge. The design principle (DP) can be defined as: "A fundamental rule or law, derived inductively from extensive experience and/or empirical evidence, which provides design process guidance to increase the chance of reaching a successful solution." (Fu et al., 2015, 2016). DPs can provide a way for utilisation of AM capabilities and can indicate efficient design. The higher the descriptions are in a hierarchy, the less restrictive they are in contrast to other forms. Therefore, in tasks where creativity and broad ideas are required, like in conceptual design, DPs are considered as suitable design guidance, and their usage can lead to an exploration of a variety of possible solutions (Pradel et al., 2018b). To overcome some limitations of previously developed approaches, this research proposes conceiving of the DPAM repository for storing of formalised AM knowledge, where DPs are classified according to functions defined through formal vocabulary. Furthermore, the study examines the possibilities of DP representation that can stimulate designer creativity. Thus, DPAM repository will be developed as a computer framework to enable multimedia forms of representation. The study also investigates the possibilities of using a physical representation of DPs for easier understanding of principles. Furthermore, a physical model can be used in DfAM approaches to stimulate the creativity of designers. Example of such approach can be found in the method proposed by Georgiev and Taura (2015) for expansion of concept space that is based on designers' interactions with materialised design ideas that are manufactured with AM. The method enables discovery of new features and functions, as well as boost designer inspiration, and can affect human feeling for the artefact from the perspective of scale.

\section{METHOD FOR EXTRACTING AM DESIGN PRINCIPLES}

To establish the repository, data about possibilities of AM in achieving both form and function from which the DPs will be derived have to be gathered. The DPs can be derived from analysis of existing designs, using existing principles found in literature, from experience of expert designers, from design practice or laboratory design practice and observation of design practice (Fu et al., 2015, 2016). 
Literature shows that most design principles are derived by analysing existing designs, followed by using existing principles from literature and deriving principles from experience of the expert designers. Other forms of deriving design principles, from design practice or laboratory design practice and observations of design experts, make up a considerably smaller share compared to previous three (Fu et al., 2015, 2016).

Following the literature conclusions regarding how the DPs are derived, the research will be based on the two most common ways of deriving DPs: from analysis of existing designs and literature review. To conceive the repository a methodology previously used by Yilmaz and Seifert (2010) as well as Blösch-Paidosh and Shea (2017) for the development of design heuristics is followed. The methodology differs from previous approaches in the source of AM designs used for derivation of DPs. It consists of four steps showed in Figure 1.


Figure 1. Method diagram

The first step of methodology for establishing the DPAM repository is based on gathering data from existing AM designs and literature review to derive DPs. The primary source of existing designs will be crowd-sourced platforms for sharing AM models, e.g. thingiverse.com, as well as other sources of AM designs and artefacts available. The crowd-sourced platforms contain thousands of CAD models that are manufacturable with AM and often contain a history of changes that improved the CAD model for AM. The focus will be on finding CAD models that are only manufacturable with AM and where the manufacturing of the artefact with AM has a significant advantage over conventional manufacturing technology. After gathering of a sample pool, CAD models will be analysed. Different users that created and modified the models, purposely, as well as unintentionally, applied various principles and solutions based on characteristics and possibilities of AM. Due to the quantity of platforms content and number of different ideas users applied in creating the content of the platform, by observing models and its modifications, a great number of DPs can be derived (Perez et al., 2015). As the designs are in digital form, an algorithm for automatization can be developed to enable easier finding of DPs. After analysis, in the process of deriving DPs, the focus will be on functions, features and forms that are based on characteristics of AM or their design and manufacturability are considerably eased by AM. DPs derived from existing designs will be complemented with the DPs found in the literature. After the initial repository is established, case and user studies will have to be conducted to validate the DPs and the DPAM repository. The validation should provide answers to questions such as, are the elements of the description understandable, are additional elements needed, is the repository structure valid, how can the repository be improved?

\section{ELEMENTS OF DESIGN PRINCIPLES REPRESENTATION}

The DPAM repository store formalised AM specific knowledge through DPs. To show the AM knowledge to the designer and aid in the understanding of AM possibilities, elements of DPs representation are needed. To enable representation of formalised AM design knowledge and to provide design process guidance, according to DP definition, five elements of DP representation are identified: Functional Classification, Description (textual and visual), 3D Model (virtual and physical model), Manufacturability Data and Examples (Figure 2). Through these elements, DPs are presented and stored in the DPAM repository. The elements of representation enable structure of DPAM repository and search for solutions based on functions. Furthermore, their purpose is to explain the DPs, stimulate designers' creativity with descriptions and examples, as well as provide information about the technical feasibility of DP. They also contain digital data needed for visualisation of a 3D model through viewer and manufacturing of physical DP models. 


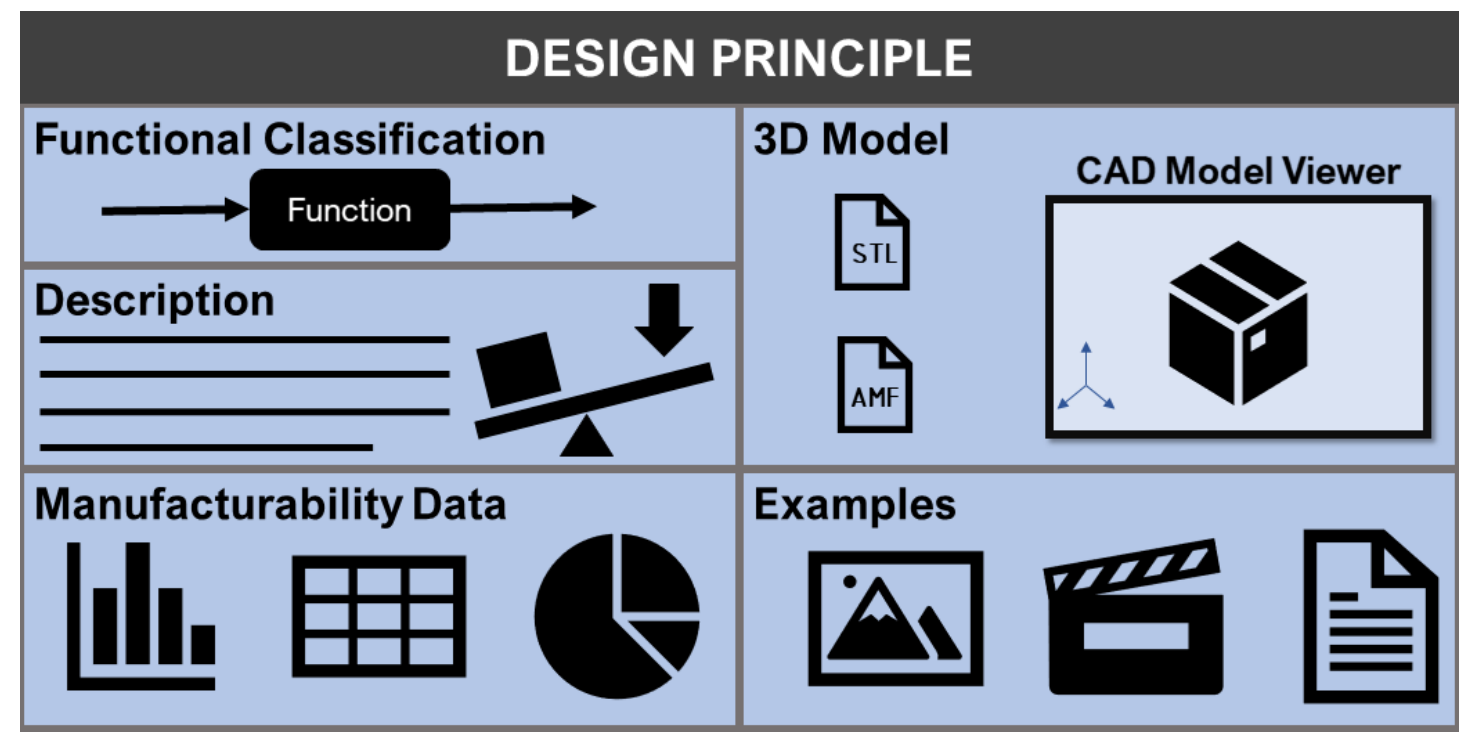

Figure 2. Layout of DP representation inside DPAM repository

\subsection{Functional classification}

The form of the product emerges from its function (Ullman, 2010) thus, analysis of product function is often used as a starting point for conceptual design. Following DfAM framework proposed by Kumke et al. (2016), conceptual design for AM products starts with the determination of products functions and their structures. This is consistent with Pahl \& Beitz's (Pahl et al., 2007) task of functional decomposition, where the overall function of the design problem is broken down into sub-functions of lower complexity that are connected with flows of material, energy and information. The function decomposition enables a better understanding of the design problem but also simplifies the search for the partial solutions that are then combined into a working structure of a product. The same approach can be used in DfAM, therefore in DPAM repository functions are used as classifying criteria for DPs to support the function-oriented conceptual design. To define the structure and later enable easier search for DPs it is essential to have a well-defined vocabulary of functions, with a limited number of possible definitions. This will ensure consistency of function definitions and enable a common understanding of functions. Therefore, in DPAM repository functions are expressed through the formal vocabulary of functions defined by Hirtz et al. (2002). Their approach offers clear taxonomy and definitions of both functions and flows. The taxonomy contains three classes of flows (material, signal, and energy) and eight classes of functions (branch, channel, connect, control magnitude, convert, provision, signal and support) that are further divided into secondary and tertiary categories. DPs classification based on the formal vocabulary of functions limits the number of possible expressions, thus simplifies the search for the suitable DP and enables application of DPAM repository in the structured methods for the conceptual design, e.g. Borgue et al. (2018), Valjak et al. (2018).

\subsection{Description}

The second element of DP representation used for capturing of AM knowledge are textual and visual descriptions. The descriptions offer an easy way of recording a variety of information about the DP, such as general and detail description of how the DP can be used as a solution for the given design problem, as well as possible applications of the DP. The textual descriptions are excellent representation form when DPs need to be described at a high level of abstraction, as designers can recognise words as concepts and derive their essence or broader meaning (Goldschmidt and Sever, 2011). The textual description is complemented with visual description (in the form of schematics and pictures) as there are ideas that are not expressible through textual description but are expressible through visual description (Goldschmidt and Sever, 2011). This is true in the opposite direction as well, thus both forms of descriptions are needed in the future repository. 


\subsection{D model}

The third element of the design principle representation is a 3D model of a principle. The 3D model comes in two forms: (i) CAD/virtual model and (ii) physical model. The first form, the CAD model, is a 3D description of the principle, but also an intermediate step towards a physical model of a principle. One of the functions of the CAD model is also to act as an intermediary between design and construction (Sass and Oxman, 2006). The CAD model of design principle can be beneficial for visualisation and perception of a principle, thus providing support for the designer to get an understanding of a principle. The future repository should incorporate a viewer of a CAD model for easy and fast examination of DPs. In the future, the CAD model could be used in virtual reality (VR) environment to enable perception of the principles in 3D without the need for their physical embodiment.

The second form of 3D model representation is the physical model. The physical model will be used for a better understanding of the DP, but more importantly, it will enable interaction with the DP. Neeley (2013) showed that the use of physical models and designers' interaction with them can accelerate ideation in early design stages. Therefore, the physical model as the element of principle representation is similar to the concept of Additive Manufacturing of Intermediate Objects (AMIO) proposed by Rias et al. (2017). AMIO should be used as Intermediate Representation (IR) in the process of AM product development. The main purpose of using physical AMIO objects is to enable designers to represent and experiment with AM concepts features and support the representation of functional complexity, thus overcoming the drawback of 3D CAD (virtual) models that do not transmit designers' intentions sufficiently. Use of physical models enables designers to feel the sensitive aspects of DP (e.g. to feel material, shape, surface texture, sensation, weight, etc.) thus stimulating designers' creativity with the experience.

\subsection{Manufacturability data}

The AM have several types of processes that differ in the form of raw materials used in the process, the source of energy used to form and bound material during deposition, as well as the way material is deposited to create an artefact (Gibson et al., 2015). Each of the processes has different characteristics and possibilities of manufacturing, thus providing different possibilities in the design. Some DPs will be derived from these specific design possibilities that are possible with a single, or only a few AM processes and will not be universally applicable in all AM processes. For example, DPs based on multi-material structures will be possible to manufacture with material extrusion and material jetting that support more than one material at the time but will not be possible with powder bed fusion process as it only supports one material in a single build. This type of information about the DPs is needed, for example, in the design of a single AM part, as the partial solutions must be manufacturable with the same AM process. Similar problematics is with the DPs derived from characteristics of the used material. For example, the DPs based on rubber-like materials cannot be used in the design of all metal part. Should new techniques or methods for AM emerge, part of the repository describing manufacturability data can be updated or new data can be added.

\subsection{Examples}

The final element of DP representation are examples of designs and products that utilise the DP. Examples provide another source of information on the lower level of abstraction, thus providing another form for easier understanding of DP. They are most useful when they show form and function (Herring et al., 2009), thus in DP representation form and function will be captured through pictures and videos of example designs and products. Examples are often used in the design process, particularly in the conceptual design phase, as a source of inspiration during the generation of concepts. Additionally, examples of previous designs are often used as a reference when designers describe a particular solution (Eckert et al., 2005), so the incorporation of examples in the DP description can support communication inside the design team.

\section{EXAMPLES OF AM DP}

In user case scenario, designers are facing a design problem where the overall function is decomposed into the sub-functions. For each sub-function, they search DPAM repository to find DPs that can be 
used as partial solutions. From elements of DP representation, they can see which function DP can solve, as well as the description of principles. Furthermore, the 3D model is used for visualisation in the digital environment but can be manufactured for interaction and easier understandings of DP. In the end, a designer can see examples of designs where DP is used and check the data regarding manufacturability.

Below are two examples of DPs that show the content and layout of proposed DPAM repository: $D P$ for conveying information through geometry (Figure 3) and DP for part consolidation with rotation around one axis (Figure 4). The examples are selected as their simplicity will not hide the elements of DP description. Furthermore, both examples are manufacturable on desktop FDM machine so physical models can be easily manufactured and initial validation of the description carried out. The DPs examples are derived from existing designs and artefacts, and are already identified in existing literature sources (Blösch-Paidosh and Shea, 2017; Perez et al., 2015).

The first example is the DP for function "display visual". The function can be found in a great number of products that need to convey visual information to users such as instructions and warnings how to safely operate with a product, but also other types of information like logos and brand visual identity. One of the possible principle solutions for this function is conveying information through geometry. AM enables manufacturing of almost any shape imaginable at insignificant or no additional cost at all, and therefore enable designs of geometry that will convey the needed information to the user. The principle is also used in conventional manufacturing technologies, such as injection moulding, but in $\mathrm{AM}$ it is not constrained in shape and positioning due to tool opening.

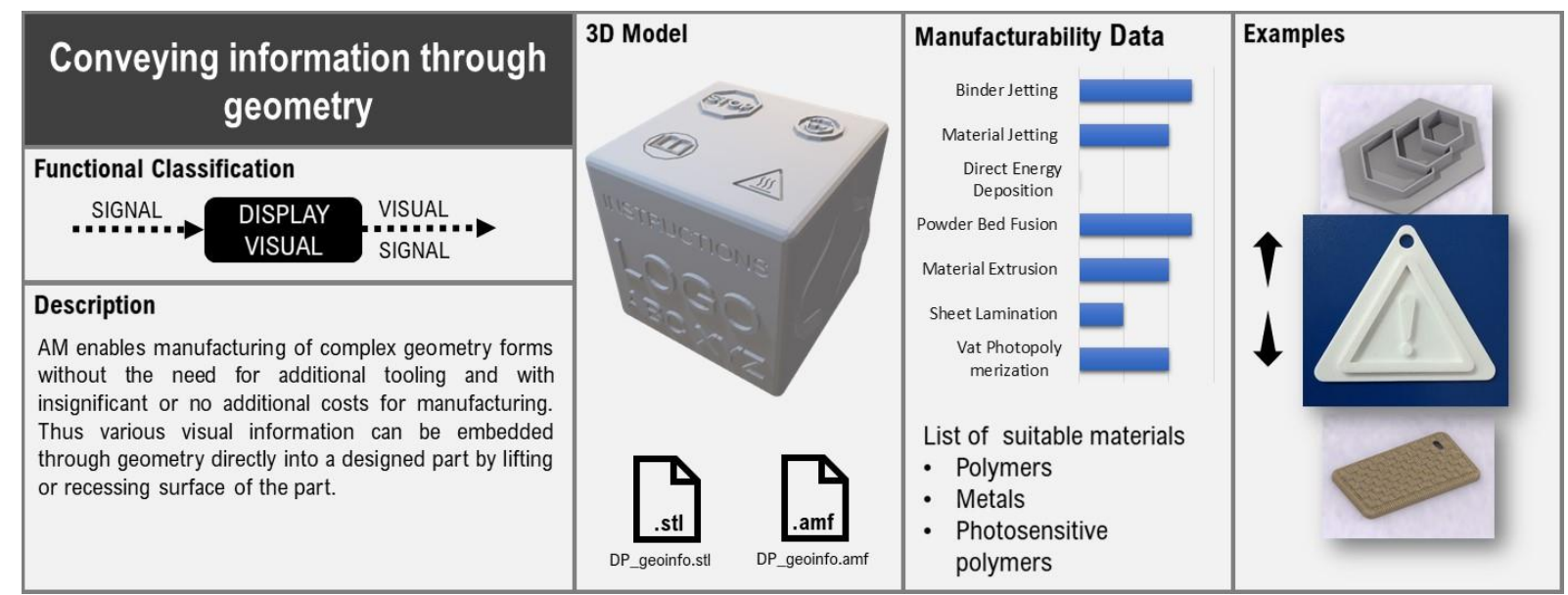

Figure 3. DP for conveying information through geometry

The second example is DP for function "rotate solid". The function is common in products that consist of two or more parts, and there is a need for one degree of freedom - rotation around one axis, e.g. box covers, hinges, etc. AM enables consolidation of parts through manufacturing of mechanisms that do not require later assembly. This DP is not possible on all AM processes as it requires support material/elements that need to be removed after manufacturing.

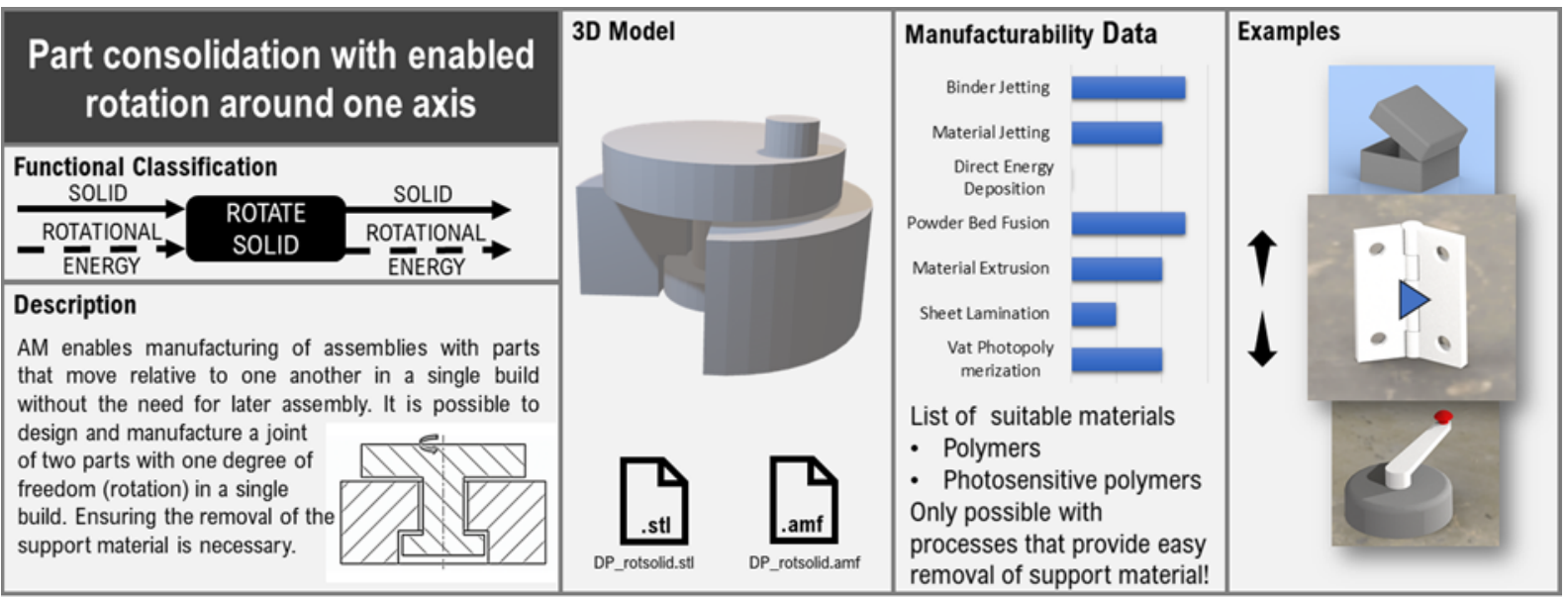

Figure 4. DP for part consolidation through rotation of a part 
Both examples show the DP's intention to solve a particular function. The elements of representation in both examples are similar, with the difference in the second example where the textual description is completed with visual description. Furthermore, the second example has an additional comment regarding manufacturability, as the DP is not achievable in all AM processes and designs, since there is a need for support material during the build that needs to be removed afterwards.

\section{DISCUSSION}

The proposed DPAM repository stores AM knowledge, formalised in the form of DPs, and enables its utilisation in early design phases. The repository and DPs support structured design process, especially the conceptual design phase in which the functional decomposition is used. In comparison to heuristics (Blösch-Paidosh and Shea, 2017; Lindwall and Törlind, 2018), that offer broad approach and guidance to solve a design problem, the DPs provide more distinctive partial solutions. While heuristics support the intuitive and creative design, DPs can extend such approach and suggest the design solutions that designers would not intuitively think of. At the same time, DPAM repository will contain a broader set of solutions on a higher level of descriptions compared to design feature database (Bin Maidin et al., 2012). DPAM repository is mostly similar to design catalogue of AM principles (Weiss et al., 2016), but differs in using the formal vocabulary for defining functions that can ease the search for the needed principles but also be used in the future structured methods for conceptual AM design. At the same time, use of formal function vocabulary for the description of DPs can is used for structuring DPAM repository, categorisation of DPs and later easier navigation through the repository. Due to its realisation in the form of computer framework, the proposed repository has extensive multimedia descriptions of DPs that can improve the understanding of AM possibilities, especially with the novice designers in AM. This is further extended with the proposed use of physical models that enable designers to interact with models of principles.

The elements of DPs representation intend to show the designers the unique AM capabilities and to stimulate their creativity during the design of AM products. Hence, elements of representation are extended beyond the textual description and include a visual description, as well as a 3D model that can be manufactured into a physical model of a DP. This is in accordance with Gonçalves et al. (2014) study that showed both design students and professional designers prefer visual representation as stimuli during design activities. The same study showed that at the same time, physical objects for representation are highly rated by the professionals, as they provide more information than other forms of representation. Therefore, physical models are used as an integral element of representation. The physical models should be simple, minimalist and abstract, but at the same time functional to enable interaction, as their purpose is to create a shared experience in the design team as they allow communication through experience rather than through language (Rias et al., 2017). Additionally, as DPs models are manufactured with the same materials and process that are used for the final product, complemented with provided manufacturability data, they play a role of an early technical validation of the generated concepts and contribute to the credibility of the concepts in the eyes of industrial stakeholders (Rias et al., 2017). Furthermore, Gonçalves et al. (2014) study showed that designers look for inspiration mostly at the beginning of the design process, especially during idea generation and conceptual design phase. Therefore, the presented approach is consistent with these conclusions as the intention of DPAM repository is to stimulate designers and provide them with partial solutions through various descriptions of DP in the early design phases. The representation of DP is supplemented with examples of previous designs as they are often used in design practice as a tool of communication inside the design teams (Eckert et al., 2005).

The elements of DPs representation, especially examples, act as stimuli that can extend the solution space and increase the number of creative solutions (Goldschmidt and Sever, 2011; Gonçalves et al., 2014). At the same time, they can cause some negative effects manifested in design fixation that limits creative ideas, as the designers are trying to replicate existing solutions (Purcell and Gero, 1996). To investigate the issue user studies will have to be conducted to see how proposed combined elements of DP representation influence designers, and is there a need to modify elements, supplement them with new elements or even remove current ones from the DPAM repository. 


\section{CONCLUSION \& FUTURE WORK}

In this work, the problem of formalising AM design knowledge and its application in the conceptual design phase is addressed. The main contribution of the paper is the proposal of DPAM repository, that categorises DPs for AM based on function criteria. The function-based approach offers the systematic structuring of the repository and supports the structured conceptual design process based on the functional decomposition of a product. Furthermore, the paper proposes a variety of elements for DP representation, from textual and schematic representation, over 3D model and examples of utilised DP, to the physical model, with focus on their influence on the process of conceptual design.

Future work will be focused on conceiving an initial repository of DPs mostly based on the DPs derived from characteristics of FDM technology. Before extending the repository to include a broader set of DPs achievable with all AM processes initial validation through the case and user studies will be conducted. Its focus will be on elements of DP representation, especially the design of physical models and its manufacturability, as well as the general structure of the repository. After establishing comprehensive repository user studies will be conducted to investigate the influence of the DPs on designers and the conceptual design process.

\section{REFERENCES}

Bin Maidin, S., Campbell, I. and Pei, E. (2012), "Development of a design feature database to support design for additive manufacturing", Assembly Automation, Vol. 32 No. 3, pp. 235-244. http://doi.org/10.1108/01445151211244375

Blösch-Paidosh, A. and Shea, K. (2017), "Design Heuristics for Additive Manufacturing”, Proceedings of the 21st International Conference on Engineering Design (ICED 17) Vol 5: Design for X, Design to X, Vancouver, Canada, August 21-25, 2017, The Design Society, Vancouver, Canada, pp. 91-100.

Blösch-Paidosh, A. and Shea, K. (2018), "Design Heuristics for Additive Manufacturing Validated Through a User Study", Journal of Mechanical Design, Vol. 14 No. 4, p. MD-17-1838. http://doi.org/10.1115/1.4041051

Borgue, O., Müller, J.R., Panarotto, M. and Isaksson, O. (2018), "Function modelling and constraints replacement for additive manufacturing in satellite components", Proceedings of NordDesign 2018, Linköping, Sweden, August 14-17, 2018, The Design Society, Linköping, Sweden, pp. 1-12.

Eckert, C., Stacey, M. and Earl, C. (2005), "References to past designs", In: Gero, J.S. and Bonnardel, N. (Eds.), Studying Designers '05, Key Centre of Design Computing and Cognition, Sydney, Australia, pp. 3-21.

Fu, K.K., Yang, M.C. and Wood, K.L. (2015), "Design Principles: The Foundation of Design", Volume 7: 27th International Conference on Design Theory and Methodology, Boston, USA August 2-5, 2015, ASME, Boston, Massachusetts, USA, p. V007T06A034. http://doi.org/10.1115/DETC2015-46157

Fu, K.K., Yang, M.C. and Wood, K.L. (2016), "Design Principles: Literature Review, Analysis, and Future Directions", Journal of Mechanical Design, Vol. 138 No. 10, p. 101103. http://doi.org/10.1115/1.4034105

Georgiev, G. V. and Taura, T. (2015), "Using Idea Materialization To Enhance Design Creativity", 20th International Conference on Engineering Design (ICED 15), Milan, Italy, July 27-30, 2015, The Design Society, Milan, Italy, pp. 1-10.

Gibson, I., Rosen, D. and Stucker, B. (2015), Additive Manufacturing Technologies, Rapid Manufacturing Association, Second Edi., Springer New York, New York. http://doi.org/10.1007/978-1-4939-2113-3

Goldschmidt, G. and Sever, A.L. (2011), "Inspiring design ideas with texts", Design Studies, Vol. 32 No. 2, pp. 139-155. http://doi.org/10.1016/j.destud.2010.09.006

Gonçalves, M., Cardoso, C. and Badke-Schaub, P. (2014), "What inspires designers? Preferences on inspirational approaches during idea generation", Design Studies, Vol. 35 No. 1, pp. 29-53. http://doi.org/10.1016/j.destud.2013.09.001

Herring, S.R., Chang, C.-C., Krantzler, J. and Bailey, B.P. (2009), "Getting inspired! Understanding How and Why Examples are Used in Creative Design Practice", Proceedings of the 27th International Conference on Human Factors in Computing Systems - CHI 09, New York, April 4-9, 2009, ACM Press, New York, New York, USA, p. 87. http://doi.org/10.1145/1518701.1518717

Hirtz, J., Stone, R.B., McAdams, D.A., Szykman, S. and Wood, K.L. (2002), “A functional basis for engineering design: Reconciling and evolving previous efforts", Research in Engineering Design, Vol. 13 No. 2, pp. 65-82. http://doi.org/10.1007/s00163-001-0008-3

Ko, H. and Moon, S.K. (2017), "Contrasting Function With Affordance in Design for Additive Manufacturing", ASME 2017 International Design Engineering Technical Conferences and Computers and Information in Engineering Conference Volume 1: 37th Computers and Information in Engineering Conference, Cleveland, Ohio, USA, August 6-9, 2017, ASME, Ohio, USA, p. V001T02A031. http://doi.org/10.1115/DETC2017-68157 
Kumke, M., Watschke, H. and Vietor, T. (2016), “A new methodological framework for design for additive manufacturing”, Virtual and Physical Prototyping, Vol. 11 No. 1, pp. 3-19. http://doi.org/10.1080/17452759.2016.1139377

Laverne, F., Segonds, F., Anwer, N. and Le Coq, M. (2015), “Assembly Based Methods to Support Product Innovation in Design for Additive Manufacturing: An Exploratory Case Study”, Journal of Mechanical Design, Vol. 137 No. 12, p. 121701. http://doi.org/10.1115/1.4031589

Lindwall, A. and Törlind, P. (2018), "Evaluating Design Heuristics for Additive Manufacturing as an Explorative Workshop Method", Proceedings of the DESIGN 2018 15th International Design Conference, Dubrovnik, Croatia, May 21-24, 2018, The Design Society, Dubrovnik, Croatia, pp. 1221-1232. http://doi.org/10.21278/idc.2018.0310

Neeley, W.L., Lim, K., Zhu, A. and Yang, M.C. (2013), "Building Fast to Think Faster: Exploiting Rapid Prototyping to Accelerate Ideation During Early Stage Design", Volume 5: 25th International Conference on Design Theory and Methodology; ASME 2013 Power Transmission and Gearing Conference, Portland, Oregon, USA, August 4-7, 2013, ASME, Portland, USA, p. V005T06A022. http://doi.org/10.1115/DETC2013-12635

Pahl, G., Beitz, W., Feldhusen, J. and Grote, K.-H. (2007), Engineering Design, Eds: Wallace, K. and Blessing, L., Third Edit., Springer, London, London. http://doi.org/10.1007/978-1-84628-319-2.

Perez, K.B., Anderson, D.S. and Wood, K.L. (2015), "Crowdsourced Design Principles for Leveraging the Capabilities of Additive Manufacturing”, 20th International Conference on Engineering Design (ICED 15), Milan, Italy, July 27-30, 2015, The Design Society, Milan, Italy, pp. 1-10.

Pradel, P., Zhu, Z., Bibb, R. and Moultrie, J. (2018a), "Investigation of design for additive manufacturing in professional design practice", Journal of Engineering Design, Vol. 29 No. 4-5, pp. 165-200. http://doi.org/10.1080/09544828.2018.1454589

Pradel, P., Zhu, Z., Bibb, R. and Moultrie, J. (2018b), “A framework for mapping design for additive manufacturing knowledge for industrial and product design”, Journal of Engineering Design, Vol. 29 No. 6, pp. 291-326. http://doi.org/10.1080/09544828.2018.1483011

Purcell, A.T. and Gero, J.S. (1996), "Design and other types of fixation”, Design Studies, Vol. 17 No. 4 SPEC. ISS., pp. 363-383. http://doi.org/10.1016/S0142-694X(96)00023-3

Rias, A.L., Segonds, F., Bouchard, C. and Abed, S. (2017), "Towards additive manufacturing of intermediate objects (AMIO) for concepts generation", International Journal on Interactive Design and Manufacturing, Vol. 11 No. 2, pp. 301-315. http://doi.org/10.5772/50570

Sass, L. and Oxman, R. (2006), "Materializing design: The implications of rapid prototyping in digital design", Design Studies, Vol. 27 No. 3, pp. 325-355. http://doi.org/10.1016/j.destud.2005.11.009

Seepersad, C.C. (2014), "Challenges and Opportunities in Design for Additive Manufacturing”, 3D Printing and Additive Manufacturing, Vol. 1 No. 1, pp. 10-13. http://doi.org/10.1089/3dp.2013.0006

Thompson, M.K., Moroni, G., Vaneker, T., Fadel, G., Campbell, R.I., Gibson, I., Bernard, A. et al. (2016), "Design for Additive Manufacturing: Trends, opportunities, considerations, and constraints", CIRP Annals-Manufacturing Technology, Vol. 65 No. 2, pp. 737-760. http://doi.org/10.1016/j.cirp.2016.05.004

Ullman, D.G. (2010), The Mechanical Design Process, McGraw-Hill Education, Boston. http://doi.org/10.1017/CBO9781107415324.004.

Valjak, F., Bojčetić, N. and Lukić, M. (2018), "Design for Additive Manufacturing: Mapping of Product Functions", Proceedings of the DESIGN 2018 15th International Design Conference, Dubrovnik, Croatia, May 21-24, 2018, The Design Society, Dubrovnik, Croatia, pp. 1369-1380. http://doi.org/10.21278/idc.2018.0364

Weiss, F., Binz, H. and Roth, D. (2016), "Conception of a design catalogue for the development of functionalities with additive manufacturing", Proceedings of NordDesign 2016, Volume 2, Trondheim, Norway, August 10-12, 2016, The Design Society, Trondheim, Norway, pp. 1-10.

Yang, S., Tang, Y. and Zhao, Y.F. (2016), "Assembly-Level Design for Additive Manufacturing: Issues and Benchmark", Volume 2A: 42nd Design Automation Conference, Charlotte, North Carolina, USA, August 21-24, 2016, ASME, p. V02AT03A028. http://doi.org/10.1115/DETC2016-59565

Yilmaz, S. and Seifert, C. (2010), "Cognitive Heuristics Use in Engineering Design Ideation”, Proceedings of DESIGN 2010, the 11th International Design Conference, Dubrovnik, Croatia, May 17-20, 2010, The Design Society, pp. 625-627. 